\title{
THE EMPHASIS OF SPELLING AND MEANING OF THE CONTEXT FOR ELONGATED REMINISCENCE
}

\author{
Dr J John Sunil Manoah \\ Academic Adviser \\ Vethathiri Maharishi Institutions, SVG Puram, Tamil Nadu, India
}

\begin{abstract}
Reminiscence is the process of recalling past experiences, learned, revived, and retained during their course of life. Which is a must quality for the students of any segment, it is also important for every human being, but with an intent not to widen the topic I diminish to stick within the boundary of students. Reminiscence is an essential quality for the students to stay among the toppers list during their course of study, the better a student remembers the lessons more the possibilities are to score high marks in exams. It's obvious that the human brain plays a vital role in reminiscence, inside it many cells and tissues denote the capability which we have not taken for discussion. This manuscript projects an ideology for a student with a normal human brain to have a good reminiscence within their accessible conditions.
\end{abstract}

Keywords - Reminiscence, Spelling, Meaning.

\section{INTRODUCTION}

The problem in reminiscence is the universal issue which can be found among all ages of students. Most of Institutions nowadays hire a memory trainer in order to equip their student's memory power. Most of the memory trainers follow the method of the cognitive approach which is a traditional method that even most of the teacher who had completed a professional training will offer the students, despite offering professional cognitive method to equip the memory of the students doesn't occur to be very successful, the reasons can be worked out with many causes but that's not the topic we are going to discuss in this article, apart from the cognitive approach the teacher can still apply some easy methods to develop the reminiscence of the students which will be discussed in this article.

\section{LEARNING APPROACH}

\section{A. Meaning and Definition of Cognitive approach}

Cognitive the word stands to mean the process of knowing and understanding. When we talk about "knowing and understanding" there are several ways to acquire it, knowing a process by the methods of Sense, Touch, Reaction, Resemblance, Outer Look, Outer Characteristics, Erupt and
Exhibitions. It is believed that our ancestors have learned and known through the cognitive approach. Understanding the process is quite different from knowing, even after knowing about a concept understanding the concept requires additional skills like Emotional Intelligence, Intuition, Instinct, Extrasensory perception (ESP), Premonition, Penetration, Presentiment, Divination, and Clairvoyance. Hence the process of knowing and understanding requires the abovementioned qualities in order to bear through the cognitive approach. This article focuses not on the cognitive approach but gives a different strategy to promote the reminiscences of students.

\section{B. The Acquirement Process of Spelling}

Spelling is an activity in which the letters appear in the word will be named one by one either in writing or reading. None can confirm that they know the correct spelling of all the words known to them. We would have observed that many doctors will maintain an ugly handwriting while writing the name of medicines in the prescription, the reason is most of the doctors are unaware of the correct spelling of the medicine names, hence they prefer scratching the name of the medicines in the prescription which could be understood only by the pharmacist. Many may think that spelling is an easy process and the students will learn when their age progress which is not true at all. Being a teacher both in school and in college with over 13 years of experience I have never corrected an answering script without a spelling mistake even from the toppers. There are two different categories of students who commit a mistake in spelling.

i. Who don't the exact spelling of the word

ii. Who write incorrectly sometimes even if they knew the correct spelling due to pressure, speed, and progressive thinking

The students who fall under the second category are minority indeed the majority of the students come under the first category. In my study, I have found most of the students who make a spelling mistake are the one who doesn't know the correct spelling of the word. The curricula of the students were framed by extreme subject experts who analyze the age of the students and measure the capability and potential of the 


\section{International Journal of Engineering Applied Sciences and Technology, 2020 \\ Vol. 4, Issue 10, ISSN No. 2455-2143, Pages 359-362 \\ Published Online February 2020 in IJEAST (http://www.ijeast.com)}

particular age group and frame the content of the lessons accordingly. Hence the words that appear in a textbook are based upon the capability according to the students' age. In such a scenario it is the duty of a student to know the correct spelling of at least $80 \%$ the words that appear in their textbooks. Nowadays in the market several kinds of extracurricular courses like spell bee, speak fluently, voice and articulation are available for the students to develop their spelling knowledge, even some of the courses are being adopted by some private institutions to develop their students spelling capability which also helps the institutions to gain good credit from the parents' side. Indeed the courses like spell bee and speak fluent help a lot to the students to develop their spelling knowledge, as it primarily focuses only on spelling. Apart from the programmed courses, there are lots of play-way methods available to increase the spelling knowledge which most of the institution follows, they are as follows.

\author{
1. Origami Fortune Teller \\ 2. Word Catcher \\ 3. Magnetic letter, Alphabet Blocks, Scrabbles \\ 4. Crossword Puzzle \\ 5. Sensory play \\ 6. Type writing practice \\ 7. Play Hangman \\ 8. Find the Missing Letter \\ 9. Arrange in ABC Order \\ 10. Newspaper Highlighting
}

All the above activities are conducted in a form of games to children which will be fun and joy while learning. Hence these activities are considered very effective for the development of spelling knowledge.

\section{The Menace of Spelling}

The spelling of the word cannot be taken lightly it is a very serious concern as far language is concerned. In fact, it is the primary element of written language. All kind of formal content in writing will undergo spell check on numerous occasions to avoid complications. Let us see some of the writings with spelling errors that have gone fun and embarrass.

Eg 1. A poster pasted in front of a building states "Toilet only for Bachelors" which is supposed to state 'Tolet' instead of 'Toilet'. In this example there is only one spelling mistake was made which gives a completely different sense from what it suppose to be.

Eg 2. In a camera advertisement, the content goes like this "Powered by lithium batteries, you'll always be ready for a shit". Here the spelling mistake is made in the word last word 'shit' which should be mentioned as 'shot'.
Eg 3. In the Newspaper post once it was headlined as "Modi in bed with Coed". Here the spelling mistake was made in the word 'Coed' which is actually 'Cold'.

Many more examples can be given to understand the importance of spelling but in all the above mentioned examples we can understand the mistake was made only in one word in fact with one change of letter in the word which has gone terribly wrong with meaning and understanding. Just in case discreet measurement has to be taken while framing a formal content.

\section{The Physical inadequacy of Reminiscence}

The actual topic taken for discussion is reminiscence which denotes the elongated memory power. Let us discuss the correlation between spelling and reminiscences. The word Dementia means as the loss of intellectual capacity, due to nonfunctional of neurons in the brain, the first stage of Dementia is memory loss, either a child or anyone in any age noticed with memory loss it should be examined physically in order to confirm whether is Dementia or not. Apart from Dementia, Amnesia is also another complicated issue that leads to memory loss. Both Dementia and Amnesia are concerned with medical issues which can be treated only the physician, whereas in this scenario the teacher can do nothing. But there are some exceptions which can be cured and rectified by the teacher itself, to which this manuscript gives a technique to the teacher to have elongated reminiscence power. There are so many reasons considered for the cause of Dementia and Amnesia, some children are born with it and some children are affected during their growth, but still, the issues like Dementia and Amnesia cannot be cured by external exercises alone.

\section{E. The Role of Technology in shaping one's Reminiscences}

Ever since technology started invading the humanity it has brought so many pros and cons among the people, we have to accept the benefits and advantages are more and adding to that we must accept that this technology had made the mankind lethargic and apathetic. The modernized computer had made the process of writing without error more easy and accurate; in fact, it does something more while drafting content. Before the invention of computer manual, writing method was followed to write content in which the writer needs to be meticulous and extra vigilant while writing in order to be error-free. When mankind prefers to be more meticulous while writing efforts were taken to learn the spelling of the words to display the content neatly and correctly but once the technology comes into use by default the brain the mankind makes them be lethargic and apathetic. Hence by default the human brain functions with effortless and won't show any mindfulness over the correct spelling since the computer itself will correct the mistake on its own. 


\section{International Journal of Engineering Applied Sciences and Technology, 2020 \\ Vol. 4, Issue 10, ISSN No. 2455-2143, Pages 359-362 \\ Published Online February 2020 in IJEAST (http://www.ijeast.com)}

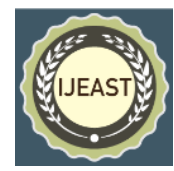

\section{F. The Potency of Spelling in shaping one's Reminiscences}

If a person had completed higher level in typewriting course, it is definite that the person will remember $80 \%$ of words to his age level. It is simply acquired by practice and by the regular use of words in typing format, but the typewriters may face one kind of problem in spelling that is they would be good in spelling only while typing not much while typing. This is power as well as the problem of the brain; it will supply the correct spelling to the writer in the format in which much practice was carried on. This also means that the brain has stored the correct spelling only in typing format if the writer wants the data in another format apart from typing the brain will not supply since it is used to provide the content only in a particular format. In this case, a question may arise why the brain could not supply the correct spelling of the word in a format which it is not used to with? The answer is simple as an interconnection of synapses happening between brain and fingers that are programmed in such a way to submit the correct spelling, it will happen only in the format that the synapses are programmed between brain and fingers, but while writing the words the functions of finger are different from the function of finger while typing. As there is a change in the synapses function the functions of the brain will also act accordingly and may differ.

Acquiring perfection in learning spelling will enable a person as a better professional especially in language skills and also helps the brain to elongate the reminiscence. It is important that the teacher must give enough practice to the students of all stages in order to gain prosper in spelling. If we see the modules of Spell Bee coaching, we can understand that they follow the method of coaching ascending order increasing the word length as one letter word, two-letter words, and threeletter words and gradually increase the word length in numbers. Every student must complete the level test in order to take-up the next level of course, without completing the first level the student cannot reach the second level, hence the criteria to reach the second level is only bypassing the first level, this guarantees the trainer that the trainee is good enough to learn a particular level. It also helps the trainer to follow a speed in coaching a particular module; age is not a criterion here to reach a level, only the knowledge matters. So once a student acquires an amount of knowledge in spelling, hardly the chances are there for the brain to refrain the correct spelling. Hence the brain recollects the correct spelling of the word anytime it needed. Therefore similarly like spell Bee coaching concept the teacher must give training to the students without having any criteria of age factor since age has got nothing to do in this kind of training. In order to provide such a kind of training, the teacher must put quite effort to design the modules and to prepare content for the modules ready at least for the first three levels. Once it was prepared then the teacher must begin with the first level to all the students in any age limit. Either the student is studying in the third standard or the student is studying in the sixth standard the same module has to be followed. The student should be allowed to reach the next level only after clearing the first level with $100 \%$. This will help the learner to stabilize with the correct spelling that will have elongated reminiscence.

\section{G. Significance of learning the meanings}

The word 'meaning' literally express what is intended to be or actually and what the understanding it gives. Meaning is considered as the most important factor in any format of content, we have discussed the significance of spelling in the above contents and understood that a little error in spelling can change the understanding of the content entirely; hence it is one step ahead of spelling as it is directly proportioned with understanding. Let us see some difference between the errors of spelling and meaning.

Table 1

\begin{tabular}{|l|l|}
\hline \multicolumn{1}{|c|}{ Spelling Error } & \multicolumn{1}{|c|}{ Meaning Error } \\
\hline Error is made by negligence & $\begin{array}{l}\text { Error is made by } \\
\text { unawareness }\end{array}$ \\
\hline $\begin{array}{l}\text { Writer may aware of the } \\
\text { meaning and still commits } \\
\text { error due to lack of } \\
\text { knowledge in language }\end{array}$ & $\begin{array}{l}\text { Writer commits error due to } \\
\text { lack of knowledge in } \\
\text { understanding. }\end{array}$ \\
\hline $\begin{array}{l}\text { Errors occur in the wordings } \\
\text { of the sentence }\end{array}$ & $\begin{array}{l}\text { Errors occur in the sense of } \\
\text { the context }\end{array}$ \\
\hline $\begin{array}{l}\text { A little change in the } \\
\text { wordings can correct the error }\end{array}$ & $\begin{array}{l}\text { The whole sentence has to be } \\
\text { reframed to change the } \\
\text { meaning. }\end{array}$ \\
\hline
\end{tabular}

Table 1 helps us to understand the differences and also the relationship between the spelling and meaning, which was very diverse intact. Good knowledge of language skill can help one to write without spelling error, whereas for meaning the good knowledge is required in understanding the sense of the context. The knowledge to understand the sense of the context requires a workout in various field and areas which is always a herculean task; one must take a lot of effort to keep him or her updated, since progress in the knowledge alone can develop one's cognitive sense. Everyday new inventions are made, new laws were enacted, new concepts were designed, and new records were set, new policies have adhered, new governments were formed, and hence News is being updated from second to second. In this fast formulating world it is always a hard job for the common people to keep them updated as there are so much of personal affairs to deal with, but still, if someone thrives to be successful there is no other choice rather updating them. 


\section{International Journal of Engineering Applied Sciences and Technology, 2020 \\ Vol. 4, Issue 10, ISSN No. 2455-2143, Pages 359-362 \\ Published Online February 2020 in IJEAST (http://www.ijeast.com)}

\section{H. The Potency of Knowing the Meanings by experiencing in personal}

Knowing the meanings does not just about understand theoretically or practically about a particular subject, it is about experiencing the knowledge in personal. The entire core expectation of life is all about having a meaningful life. If someone doesn't know the meaning of a particular word, the primary available source is to surf the dictionary which can explain the term literally. In this case, language is an essential tool to understand the meanings of words literally. If someone is not familiar with languages then they have to be dependent on others to know the meanings literally, in such a depending situation authentication and accuracy doesn't stand high in knowing the meaning. Knowing the meaning of words literally is entirely different from knowing by understanding it. Whereas understanding the meaning of the words completely depend upon the experience of a person had towards it. For e.g. the meaning of the word 'fire' literally states "a process, or instance of combustion in which fuel or other material is ignited and combined with oxygen, giving off light, heat, and flame".

Both ' $A$ ' and ' $B$ ' have never seen or experienced fire in their life, ' $A$ ' had learnt the dictionary meaning of the word fire as mentioned above, but 'B' hasn't got a chance to refer dictionary but he had seen and even felt the heat of fire in personal, among the both ' $\mathrm{B}$ ' would be having a better knowledge and understanding about fire than ' $A$ '. This illustration will explain the difference between theoretical learning and practical learning.

\section{CONCLUSION}

The process of Reminiscence can be acquired by everyone, in some cases, it is acquired slowly and in some cases it is acquired quickly. What matters the most is it has to be acquired for sure for the betterment of potential success. Learning the spelling of words and their meaning will help us to have better reminiscences.

\section{REFERENCE}

[1] Manoah. J John. "Formulas for being expertise in classroom and students handling." IRA International Journal of Education and Multidisciplinary Studies (ISSN 2455-2526) [Online], 3.1 (2016): n. pag. Web. 4 Oct. 2016

[2] Manoah, John Sunil. "The scheme of implementing Active Learning Methodologies for the students of rural areas." IJAR Indian Journal of Applied Research (ISSN 2249-555X) Vol 1, Issue 10 Oct. 2016

[3] Manoah, J. J. S., \& John, J. (2015). Formulas for Effective Teaching and Classroom Management. Language in India, 15(2).
[4] Aloudat, Asma. (2017). Spelling Errors in English Writing Committed by English-Major Students at BAU. Journal of Literature, Languages and Linguistics. 32.

[5] Rasappan, Suresh \& Manoah, John. (2018). Activity based learning for slow learners in colleges through mollycoddle method. Indian Journal of Public Health Research \& Development. 9. 1957. 10.5958/09765506.2018.01739.4.

[6] Manoah John Sunil. (2020). "Analysis on home environment and social maturity of senior school students." International Journal of Engineering Applied Sciences and Technology, (IJEAST) ISSN No. 2455-2143, 2020 Vol. 4, Issue 9, Pages 212-216.

[7] Manoah, J. (2016). A Review of Multi Nation Companies Sample Interview Task for English Language Trainers. 3. 10.21013/jems.v3.n1.p1.

[8] Manoah, J. (2016). Formulas for being expertise in classroom and students handling. 3. 10.21013/jems.v3.n1.p3.

[9] Manoah, J.J., \& Tech, V. (2014). Formulas to overcome the barriers of English proficiency for second language learners. 